J. Lake Sci.(湖泊科学), 2009, 21(1): 101-109

http://www.jlakes.org. E-mail: jlakes@niglas.ac.cn

(C2009 by Journal of Lake Sciences

\title{
南亚热带富营养化抽水型水库轮虫的组成与动态
}

\author{
王晓辉, 望 甜, 林秋奇, 韩博平 ${ }^{* *}$
}

(暨南大学水生生物研究所, 广州 510632)

摘 要: 大镜山水库位于广东省珠海市, 是一座供应珠海市和澳门特别行政区饮水的抽水型中型水库. 抽水改变了水体的水 动力过程以及水体生态系统的动态过程. 为了解这一动态过程中轮虫的群落结构及环境因子对轮虫的影响, 于 2005 年 1-12 月, 每月一次对该水库敞水区进行了采样调查. 共采集到轮虫 32 种, 其中, 臂尾轮科 12 种, 异尾轮科、腔轮科各有 4 种, 它 们主要是热带、亚热带地区的常见种和优势种类. 热带龟甲轮虫(Keratella tropica)、对棘异尾轮虫(Trichocerea stylata)、螺形 龟甲轮虫 (Keratella cochlearis)、迈氏三肢轮虫(Filinia maior)、裂痕龟纹轮虫(Anuraeopsis fissa)、角突臂尾轮虫(Brachionus angularis)、剪形臂尾轮虫(Brachionus forficula)、卵形无柄轮虫(Ascomorpha ovalis)、敞水胶鞘轮虫(Collotheca pelagica) 和卜 氏晶囊轮虫 (Asplanchna brightwelli) 为优势种, 这些优势种个体小、具有硬被甲. 轮虫的多样性指数在 0.29-0.81 之间变动, 与 相同营养水平的湖泊相比, 大镜山水库轮虫的种类数和多样性指数均较低. 轮虫丰度和生物量的分布范围分别为 21-1094ind./L 和 4.04-1127 $\mu \mathrm{g} / \mathrm{L}$, 高峰期均出现在 2 月和 5 月, 二者具有相似的动态特征. 轮虫个体的大小范围在 50-620 $\mu \mathrm{m}$ 之间, 轮虫种类和丰度的组成均以 $200 \mu \mathrm{m}$ 以下的小型个体为主, 如裂痕龟纹轮虫、角突臂尾轮虫等. 轮虫生物量组成主要是

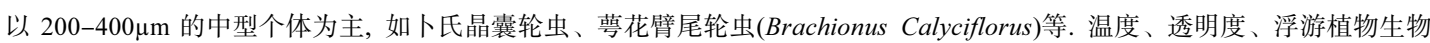
量和蓝藻生物量是影响水库轮虫群落结构特征和动态的主要环境因子.

关键词: 轮虫; 群落结构; 富营养化; 抽水型水库; 大镜山水库

\section{Species composition and quantitative dynamics of rotifers in a pumped storage, eutrophic reservoir in South China}

\author{
WANG Xiaohui, WANG Tian, LIN Qiuqi \& HAN Boping \\ (Institute of Hydrobiology, Jinan University, Guangzhou 510632, P.R.China)
}

Abstract: Dajingshan Reservoir, located in Zhuhai City, South China, is a medium-size water body. It supplies drinking water for the Zhuhai City and Macau in dry seasons. Water is pumped into the reservoir from a nearby river in dry seasons so as to enhance the water storage. Pumped water modified the hydrodynamic processes and ecosystem dynamics. In order to understand the dynamic of rotifer community and the relationships between specific composition of rotifers and the environmental variables, an investigation was conducted monthly in 2005. Altogether 32 species of rotifer were identified, among which 12 species were belonged to Brachionidae, 4 species to Trichocereidae and 4 species to Lecanidae. The majority of the species are tropical or sub-tropical species Keratella tropica, Trichocerea stylata, Keratella cochlearis, Filinia maior, Anuraeopsis fissa, Brachionus angularis, Brachionus forficula, Ascomorpha ovalis and Collotheca pelagica were the dominant species. They had small body size and lorica. The diversity index of rotifers ranged from 0.29 to 0.8 , which were lower than that in Lake Donghu and Lake Xinghu. The abundance and biomass of rotifers ranged from 21 to $1094 \mathrm{ind} . / \mathrm{L}$ and from 4.04 to $1127 \mu \mathrm{g} / \mathrm{L}$, respectively. The maximal abundance and biomass occurred in February and May, respectively. The body length of rotifers ranged from $50 \mu \mathrm{m}$ to $620 \mu \mathrm{m}$. The total abundance of rotifers was contributed by of small-sized species with a body size less than $200 \mu \mathrm{m}$, while the rotifers biomass was dominated by medium-sized

* 国家自然科学基金项目(U0733007, 30670345)资助. 2008-05-19 收稿; 2008-10-08 收修改稿. 王晓辉, 女, 1977 年生, 博 士; E-mail: wangxh1977@126.com.

** 通讯作者; E-mail: tbphan@jnu.edu.cn. 
species with body size from $200-400 \mu \mathrm{m}$. Secchi disk depth, temperature, total phytoplankton biomass and Cyanophyta biomass were the main factors affecting the species composition and quantitative dynamics of the rotifer community.

Keywords: Rotifer; species composition; dynamic; Dajingshan Reservoir

轮虫广泛分布于水库、湖泊等自然水体，其发育时间快、生命周期短、对水质敏感，能作为指示生 物较好地反映水质状况 ${ }^{[1-2]}$, 在环境监测和生态毒理研究中被广泛采用 ${ }^{[3-5]}$. 长期以来, 我国对于轮虫的研 究, 主要集中在温带和北亚热带地区, 如东湖 ${ }^{[6]}$ 、太湖 ${ }^{[7]}$ 和西湖 ${ }^{[8-9]}$ 等, 而对热带和热带-亚热带地区水库 中轮虫的研究较少 ${ }^{[10-12]}$.

广东省地处热带-亚热带地区, 水库是主要的供水水源. 近 20 年来随着经济的迅速发展, 污废水排放量 大幅度增长, 部分水库水质日趋下降, 富营养化趋势明显, 而轮虫作为反映营养状态的重要类群, 研究其在 水库中的物种多样性和动态变化对了解水库生态系统健康评估和水质监测具有重要的意义. 在广东省沿海 地区，由于河流短小，自然蓄水难以满足供水需求，有不少水库在枯水期从流域外抽调河水入库，这些抽水 型水库承担着重要的供水任务. 大镜山水库作为广东省一座中型抽水水库, 在水动力学上不同于其它河流 型水库, 抽水不仅改变了水库原有的水文节律, 而且使生态系统的动态过程也随之发生变化. 在抽水型水 库中, 水体中轮虫的种类多样性和群落结构是否与其它水体存在明显的差异?特别是随着富营养化水平的 提高, 这类水库的轮虫种类多样性和群落结构具有什么特点, 调水等环境因子又是怎样影响其变化? 针对这 些问题, 本文以大镜山水库为对象, 对该水库的轮虫群落结构进行了周年的研究.

\section{1 材料和方法}

\section{1 水库概况}

大镜山水库地处亚热带地区 $\left(22^{\circ} 17^{\prime} 43.1^{\prime \prime} \mathrm{N}, 113^{\circ} 32^{\prime} 59.4^{\prime \prime} \mathrm{E}\right)$, 位于珠海市中心, 是一座中型抽水型水 库, 担负着珠海市和澳门的供水任务. 水库水体温度全年在 $15-32^{\circ} \mathrm{C}$ 之间, 总库容为 $12.10 \times 10^{6} \mathrm{~m}^{3}$, 集雨 面积为 $5.95 \mathrm{~km}^{2}$, 年调节水量为 $49.02 \times 10^{6} \mathrm{~m}^{3}$. 由于无人库河流, 抽水成为大镜山水库人库水量的主要来 源, 且受季风气候的影响, 降雨主要集中在 $5-8$ 月, 多年平均降雨量为 $1991 \mathrm{~mm}$, 因此调水主要集中在枯 水期, 而抽水带来了较高的营养盐负荷, 导致水库水质下降.

\section{2 采样点与采样时间}

于2005年1-12月, 每月于水库大坝前水域进行一次采样.

\section{3 理化因子的测定}

用YSI水质仪现场测定水温(T); 用萨克斯盘测定透明度 $(\mathrm{SD})$; 用 $\mathrm{pHS}-3 \mathrm{C}$ 酸碱度计测定水体的 $\mathrm{pH}$ 值. 水化指标总磷 $(\mathrm{TP})$ 、总氮 $(\mathrm{TN})$ 按照国家水质标准方法GB3838-2002进行测定. 叶绿素a采用经过 $0.45 \mu \mathrm{m}$ 的 纤维滤膜抽滤 $500 \mathrm{ml}$, 反复冻融-浸提, 运用改进的丙酮萃取方法进行测定 ${ }^{[13]}$. 降雨量(Precipitation)和水 位 (Water-level) 由水库管理处提供. 浮游藻类生物量的数据由李秋华等 ${ }^{[14]}$ 提供.

\section{4 轮虫的采集、鉴定与计数}

轮虫定性样品用 $25^{\#}$ 浮游生物网 $(\Phi 64 \mu \mathrm{m})$ 于水平及垂直方向拖网; 定量样品在湖泊区从表层 $0.5 \mathrm{~m}$ 往 下每隔 $1 \mathrm{~m}$ 采水 $5 \mathrm{~L}$ 至 $10 \mathrm{~m}$ (温跃层)处, 共采水 $50 \mathrm{~L}$ 并混合均匀, 用 $\Phi 38 \mu \mathrm{m}$ 浮游生物网当场过滤, 所有样品均 用 $5 \%$ 的福尔马林溶液固定，带回实验室浓缩，在解剖镜下鉴定种类，在显微镜下计数. 轮虫种类的鉴定 按Koste分类系统. 根据浮游动物体积近似计算公式 ${ }^{[15]}$, 测定轮虫的体长、体宽以计算每个个体体积, 并 认为浮游动物密度与水相同, 从而得出每个个体的湿重, 最后计算浮游动物的生物量.

\section{5 数据分析}

Shannon-Weaver多样性指数的计算采用下列公式计算:

$$
H^{\prime}=-\sum_{i=1}^{S} p_{i} \log _{2}\left(p_{i}\right)
$$

式中, $S$ 为轮虫种数. 典范相应分析 (CCA分析)具有能同时结合多个环境因子, 分析群落与环境因子间复 
杂关系. 在环境因子特征变量构成的空间上, 对环境变量和群落等排序作图, 实现了群落与环境因子的 对应排序. 对主要轮虫种类的丰度在主轴上排序, 则可反映这些轮虫与环境因子之间的对应关系. 因此 环境因子对轮虫群落结构的影响用CANOCO软件进行CCA分析.

\section{2 结果与分析}

\section{1 环境因子}

大镜山水库主要环境因子的周年动态变化见图 1. 大镜山水库水温常年较高, 最低水温 $16^{\circ} \mathrm{C}$, 在 3 月 末出现明显的热分层. 总氮浓度变化范围为 $0.49-1.69 \mathrm{mg} / \mathrm{L}$, 总磷为 $0.01-0.08 \mathrm{mg} / \mathrm{L}$, 营养盐整体上冬春季 比夏秋季高. 8-9月总氮、总磷的浓度达到全年最低值(图 1a). 透明度变化范围为 $0.4-1.3 \mathrm{~m}, 5$ 月份透明度最 低, 为 $0.48 \mathrm{~m} ; \mathrm{pH}$ 值为 $7.45-9.15$. 水库 $5-8$ 月份为丰水期, 此期调水较少, 水库人库主要来自降雨, 因此水 位在4-8月份也较低，而枯水期(冬春季)，为保证在枯水期城市供水，特别是咸潮期的供水，增加淡水的 蓄水量, 调水人库量超过水库的供水量, 这样在 $10-11$ 月水位达到最高值, 为 $20 \mathrm{~m}$ (图 $1 \mathrm{~b})$. 叶绿素a浓度变 化范围为13.44-59.96 $\mathrm{g} / \mathrm{L}$, 冬春季较高, 夏秋季较低(图 1c). 藻类生物量除1、3月份由硅藻占优势，8、9 月份由甲藻占优势外, 其余月份由蓝藻生物量占优势(图1d).
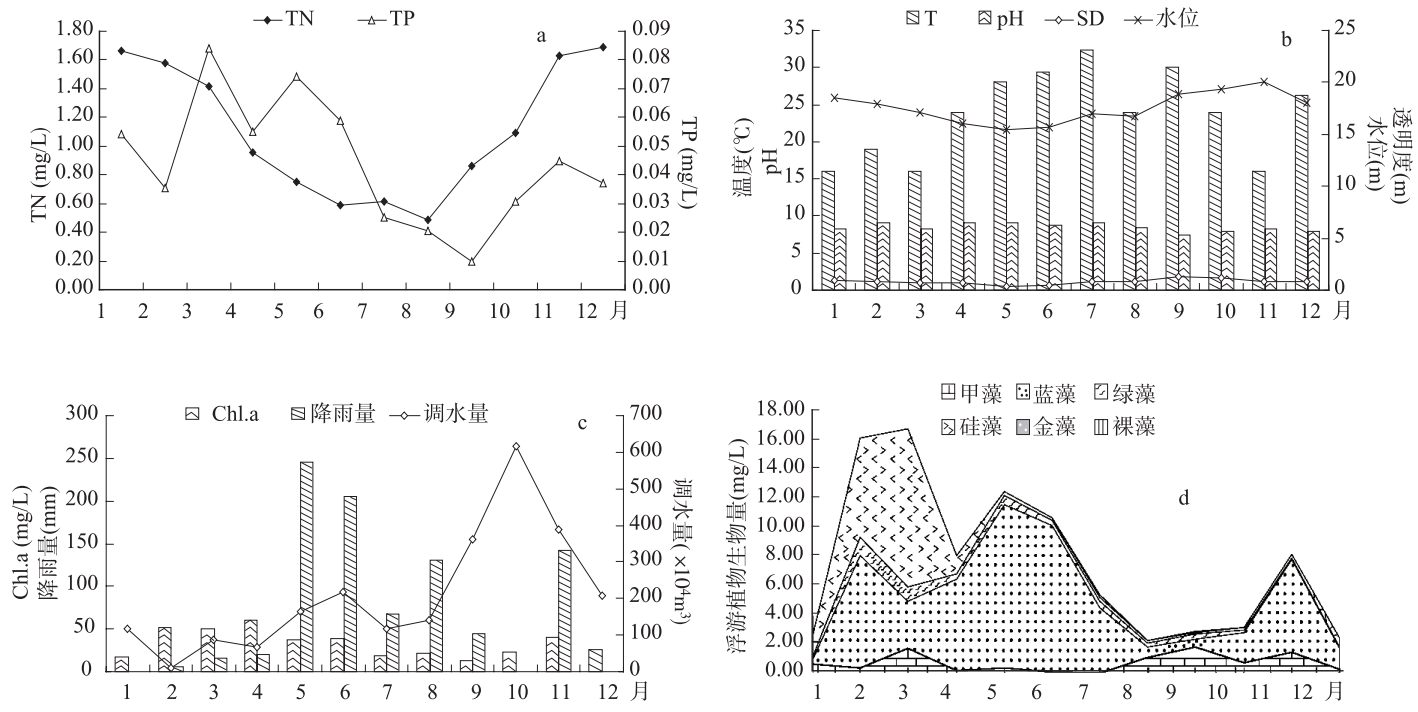

图 1 大镜山水库环境因子的变化: 总氮-总磷浓度(a); 温度、酸碱度、透明度和水位(b); 叶绿素 $\mathrm{a}$ 浓度、降雨量和调水量(c); 浮游植物生物量(d)

Fig.1 Dynamic of environment factors in Dajingshan Reservoir: total nitrogen and total phosphorus concentration(a); Temperature, $\mathrm{pH}$, Secchi disk depth and water-level(b); Chlorophyll-a concentration, precipitation and inflow(c); phytoplankton biomass $(\mathrm{d})$

\section{2 种类组成}

12次采样共采集到轮虫 32 种, 绝大多数隶属于单巢类. 其中, 臂尾轮科 12 种, 腔轮科 4 种, 异尾轮科 4 种, 腹尾轮科 2 种, 三肢轮科 2 种, 晶囊轮科、六腕轮科、聚花轮科、猪吻轮科、水轮科、胶鞘轮科、疮毛 轮科各1种. 蛭态总目只鉴定到轮虫属1个属.

轮虫的种类数在春夏季较高, 最高出现在 4 月; 秋冬季种类数较低, 最低出现在 11 月. 常见种有热带 龟甲轮虫 (Keratella tropica)、对棘异尾轮虫(Trichocerca stylata)、螺形龟甲轮虫 (K. cochlearis)、裂痕龟纹 轮虫(Anuraeopsis fissa)、角突臂尾轮虫 (Brachionus angularis)、剪形臂尾轮虫 (B. forficula)、卵形无柄轮虫 (Ascomorpha ovalis)、敞水胶鞘轮虫(Collotheca pelagica)、裂足臂尾轮虫(B. diversicornis)、蔡花臂尾轮虫 
(B. Calyciflorus)、卜氏晶囊轮虫(Asplanchna brightwelli)、圆筒异尾轮虫( T. capucina)、罗氏异尾轮虫 $(T$. rousseleti)、暗小异尾轮虫 $(T$. pusilla $)$ 和广生多肢轮虫 (Polyarthra trigla), 其中大部分为热带亚热带常见种, 并且大部分为小型的、具有硬的背甲的轮虫. 一些种类由于丰度低, 因此只在个别月份的水样中被采集到, 如蒲达臂尾轮虫(B. budapestinensis)、叉角拟聚花轮虫(Conochiloides dossuarius)和水轮虫(Epiphanes sp.)仅在 2月份; 四齿单趾轮虫(Lecane quadridentata)仅出现在4月份; 钳形猪吻轮虫(Dicranophorus forcipatus)仅在6 月份; 镰状臂尾轮虫 (B. falcatus) 仅在10月份; 轮虫属(Rotaria sp.)仅在12月份. 另外, 西氏三肢轮虫(Filinia novaezealandiae)只在3、4、5月份水样中，它是狭温性种类，主要分布在热带和亚热带地区.

由于水样采集于敞水区, 所以检测到的轮虫以营浮游生活的种类为主, 仅有 4 种腔轮虫和钳形猪吻 轮虫为附着种类(表略).

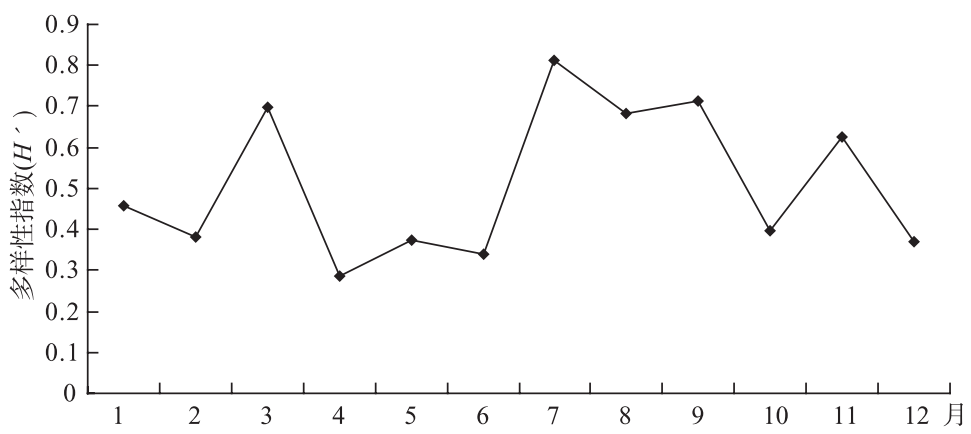

图 22005 年大镜山水库轮虫多样性指数

Fig.2 Diversity indexes of rotifer every month in Dajingshan Reservoir in 2005

大镜山水库全年各月的 Shannon-Weaver 多样性指数, 大镜山水库全年的多样性指数在 $0.29-0.81$ 之 间，多样性指数低，而 Shannon-Weaver 多样性指数在 0-1 时, 认为水质为重度污染, 因而从 Shannon-Weaver 多样性指数来看, 大镜山水库的水污染严重(图 2).

\section{3 现存量}

2.3.1 总丰度 大镜山水库轮虫丰度在21-1094ind./L内变动, 具有春夏(3-8月)高、秋冬(9-2月)低的动态特 点, 其中春、夏季轮虫丰度占全年轮虫总丰度的 $86.6 \%$. 轮虫丰度的高峰出现在春、夏两季中, 春季高峰 出现在 2 月, 丰度为 $1094 \mathrm{ind} . / \mathrm{L}$; 夏季高峰出现在 5 月, 丰度为 $663.2 \mathrm{ind} . / \mathrm{L}$, 春季高峰丰度值明显高于夏季 (图3a). 轮虫的体长范围在50-620 $\mu \mathrm{m}$ 之间, 最小个体为裂痕龟纹轮虫, 体长在 $50-80 \mu \mathrm{m}$ 之间变动; 最大个 体为卜氏晶囊轮虫, 体长在 $200-620 \mu \mathrm{m}$ 之间变动. 体长在 $200 \mu \mathrm{m}$ 以下的个体数量占绝对优势; 其次为 200-400 $\mu \mathrm{m}$ 的个体; 体长在 $400 \mu \mathrm{m}$ 以上的个体很少出现(图3b).

形成春、夏季的两个数量峰值的种类组成不同(表1). 在大镜山水库春季(2月)的高峰组成中, 对棘异 尾轮虫为第一优势种，丰度为 $364.5 \mathrm{ind} . / \mathrm{L}$; 第二优势种为广生多肢轮虫，丰度为 $121.5 \mathrm{ind} . / \mathrm{L}$. 在夏季 (5月) 的高峰组成中, 第一优势种为裂痕龟纹轮虫, 丰度为 $168 \mathrm{ind} . / \mathrm{L}$, 第二优势种为热带龟甲轮虫, 丰度为 128.8ind./L; 而且组成春、夏季高峰的种类都是广温性种类.

2.3.2 优势种的丰度 大镜山水库轮虫的优势种表现出了季节变化(表2). 根据单个种类全年丰度的平均值, 当单个种类的优势度达到 $10 \%$ 时, 将其定为优势种. 因此, 大镜山轮虫优势种主要为热带龟甲轮虫、对棘 异尾轮虫、螺形龟甲轮虫、裂痕龟纹轮虫、卜氏晶囊轮虫、角突臂尾轮虫和圆筒异尾轮虫, 此外还有剪 形臂尾轮虫、迈氏三肢轮虫、广生多肢轮虫、莒花臂尾轮虫、敞水胶鞘轮虫和卵形无柄轮虫等(图4). 其 中，龟甲轮虫(包括热带龟甲轮虫和螺形龟甲轮虫)除4月份、8月份和 10 月外，在全年其它月份均保持较高 的丰度; 异尾轮虫(包括对棘异尾轮虫、圆筒异尾轮虫和暗小异尾轮虫)除 3 月、8月外，在全年其它月份均 保持较高的丰度; 而臂尾轮虫在温度较高的季节其丰度占绝对优势. 不同种类的轮虫其相对丰度随季节 变化而波动. 在 $1 、 2 、 3$ 和 $7 、 8 、 9$ 月, 轮虫丰度总是由一种或两种轮虫占绝对优势, 其中, $1 、 2 、 3$ 月由龟 甲轮虫或龟甲轮虫与异尾轮虫构成优势种； 7、8、9月臂尾轮虫占绝对优势. 而 $4 、 5 、 6$ 月和 $10 、 11 、 12$ 
月则每种优势轮虫的相对丰度比较均衡.
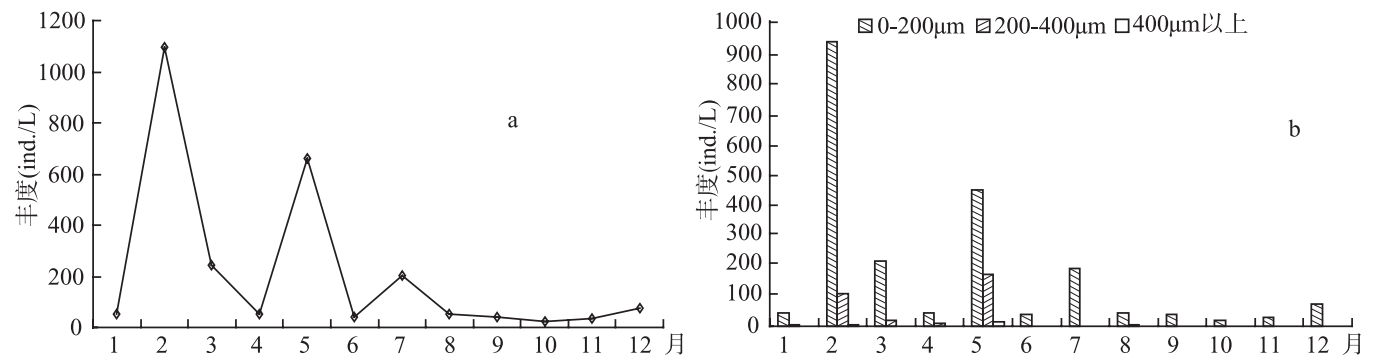

图3 大镜山轮虫丰度的季节变化: 总丰度(a); 不同体长的丰度(b)

Fig.3 Dynamics of the abundance of rotifers in Dajingshan Reservoir: Total abundance(a); Abundance in body length classes(b)

表 12005 年 1-12 月轮虫主要种类的平均丰度(2005)

Tab.1 Mean density of the dominant rotifers of the Dajingshan Reservoir in 2005

\begin{tabular}{lllll}
\hline 月份 & 优势种 & 丰度(ind./L) & 次优势种 & 丰度(ind./L) \\
\hline 1 & 热带龟甲轮虫 K. tropica & 27.1 & 囊形单趾轮虫 L. bulla & 8.5 \\
2 & 对棘异尾轮虫 T. stylata & 364.5 & 广生多肢轮虫 P. trigla & 121.5 \\
3 & 螺形龟甲轮虫 K. cochlearis & 130 & 卜氐晶囊轮虫 A. brightwelli & 22 \\
4 & 迈氏三肢轮虫 F. maior & 8.75 & 暗小异尾轮虫 T. pusilla & 7 \\
5 & 裂痕龟纹轮虫 A. fissa & 168 & 热带龟甲轮虫 K. tropica & 128.8 \\
6 & 迈氏三肢轮虫 F. maior & 8.5 & 敞水胶鞘轮虫 C. pelagica & 7.5 \\
7 & 角突臂尾轮虫 B. angularis & 54.75 & 剪形臂尾轮虫 B. forficula & 36.75 \\
8 & 剪形臂尾轮虫 B. forficula & 25.75 & 卵形无柄轮虫 A. ovalis & 9.25 \\
9 & 剪形臂尾轮虫 B. forficula & 23 & 热带龟甲轮虫 K. tropica & 5.5 \\
10 & 敞水胶鞘轮虫 C. pelagica & 5.4 & 卵形无柄轮虫 A. ovalis & 4.4 \\
11 & 热带龟甲轮虫 K. tropica & 15.5 & 剪形臂尾轮虫 B. forficula & 10 \\
12 & 卵形无柄轮虫 A. ovalis & 17 & 对棘异尾轮虫 T. stylata & 16 \\
\hline
\end{tabular}

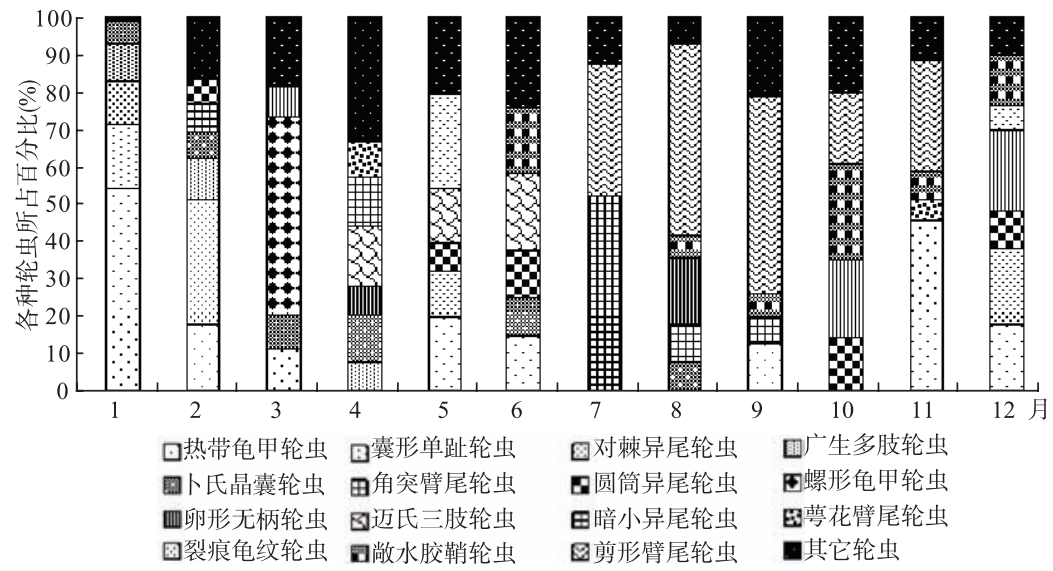

图 4 大镜山轮虫优势种相对丰度的动态变化

Fig.4 Dynamics of the relative abundances of the dominant rotifers in Dajingshan Reservoir, 2005 
2.3.3 生物量 大镜山水库轮虫生物量变化范围在 4.04-1127 $\mu \mathrm{g} / \mathrm{L}$ 内, 具有与丰度相似的动态特征(图 $5 \mathrm{a}$, 图 3a). 2 月的生物量最高, 达 $1127 \mu \mathrm{g} / \mathrm{L} ; 5$ 月出现另一个高峰, 生物量为 $810 \mu \mathrm{g} / \mathrm{L} .1-8$ 月的生物量主要由 $200-400 \mu \mathrm{m}$ 个体的生物量组成，卜氏晶囊轮虫是这个体长等级的主要种类; 而 9-12 月的生物量由 $200 \mu \mathrm{m}$ 以下的个体组成, 这个时期卜氏晶囊轮虫的数量极少(图 $5 b$ ).
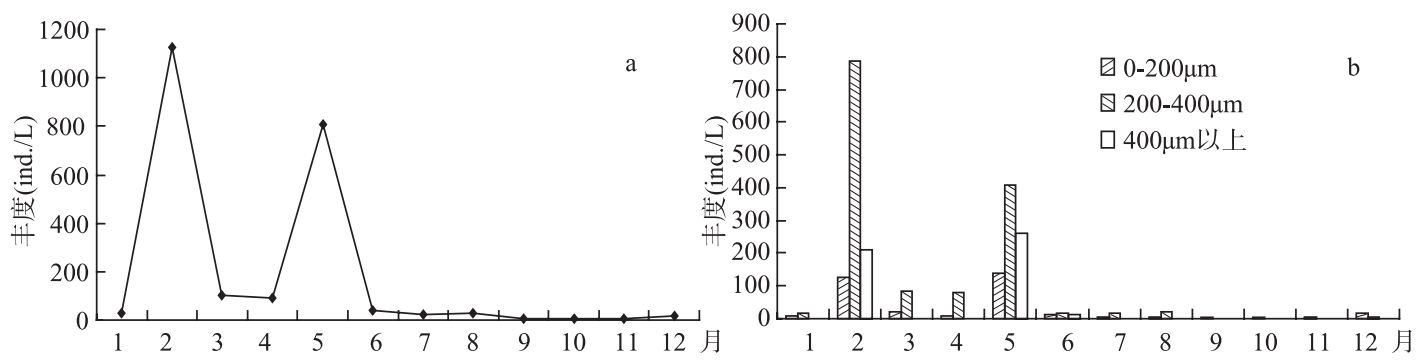

图 5 大镜山轮虫生物量的动态变化(2005 年 1-12 月): 总生物量(a); 不同体长的生物量(b)

Fig.5 Dynamics of biomass of rotifers in Dajingshan Reservoir in 2005 Total biomass(a); Biomass in body length classes(b)

\section{4 主要轮虫的丰度与环境变量的关系}

根据轮虫丰度和出现的频率, 选取 14 种主要轮虫种类, 这 14 种轮虫的丰度占水库轮虫总丰度的 95.67\%. 利用 CCA 方法, 分析了这 14 种轮虫丰度与各种生物与非生物变量之间的关系(图 6).

总氮、叶绿素 a 浓度、枝角类丰度和桡足类丰度与轴 2 呈正相关, 调水量、降雨量和温度与轴 2 呈 负相关; 透明度与轴 1 呈正相关, 蓝藻生物量、浮游植物生物量和总磷与轴 1 呈负相关. 总体来看, 蓝藻 生物量、浮游植物生物量、温度和透明度的贡献较大, 是影响轮虫群落结构的主要因子; 而总氮、总磷、 降雨量、调水量、叶绿素 $\mathrm{a}$ 浓度、桡足类和枝角类的贡献较小, 为次要因子.

\section{3 讨论}

\section{1 轮虫的种类多样性与群落结构特征}

热带-亚热带地区和温带地区轮虫在种类组成上的差异主要是来自于腔轮属、臂尾轮属和异尾轮属, 这3个属的种类是热带和亚热带地区的常见种和优势种类 ${ }^{[16]}$ ，也是该地区轮虫种类的主要组成部分 ${ }^{[17-20]}$. 在温带地区, 这些属也有分布, 但只有少数几种. 大镜山水库是一座抽水型水库, 地处热带-亚热带地区, 全年的最低水温在 $16^{\circ} \mathrm{C}$ 左右, 从水库中轮虫种类组成来看, 它们中的绝大多数为广温性种类, 兼具一些 嗜热种. 种类组成以臂尾轮属、异尾轮属和腔轮属为主, 其种类共占检到种类的 $42.4 \%$, 其中臂尾轮属有 7 种, 比较常见的有萝花臂尾轮虫、剪形臂尾轮虫、裂足臂尾轮虫和角突臂尾轮虫. 异尾轮属最常见的种 有对棘异尾轮虫、圆筒异尾轮虫、罗氏异尾轮虫和暗小异尾轮虫; 腔轮科最常见的种为囊形单趾轮虫. 在 种类上, 大镜山水库的轮虫组成与广东省其它热带亚热带水库的组成基本一致 ${ }^{[10]}$. 龟甲轮属、巨头轮属、 叶轮属和疾毛轮属在热带和亚热带地区也有分布, 并且一些种类分布相当广泛或为热带地区特有种(如 热带龟甲轮虫), 但绝大多数种类主要分布于温带地区 ${ }^{[21]}$. 大镜山水库中的龟甲轮属在种类和数量上都较 少, 只有热带龟甲轮虫和螺形龟甲轮虫为常见种, 且这两种轮虫在同地区其它水库也为常见种 ${ }^{[10]}$.

\section{2 轮虫的群落结构与水体营养水平}

关于轮虫的指示种, 不同的学者有不同的观点 ${ }^{[22-23]}$. 一般认为, 尖尾疮毛轮虫 (Synchaeta stylata)、郝 氏皱甲轮虫(Ploesoma hudsoni)、柱足腹尾轮虫、卵形无柄轮虫和独角聚花轮虫 (C. unicornis)是寡营养水 体的优势种; 中营养水体种类较多, 一般为过渡种; 臂尾轮虫、裂痕龟纹轮虫、沟痕泡轮虫 (Pompholyx sulcata)、异尾轮虫、长三肢轮虫 ( $F$. longiseta) 、奇异六腕轮虫、多肢轮虫和螺形龟甲轮虫等是富营养水 体的优势种. 以上 8 种富营养指示种中, 臂尾轮虫、裂痕龟纹轮虫、异尾轮虫、多肢轮虫和螺形龟甲轮虫 等 5 个种类是大镜山水库中的优势种. 因此, 从轮虫群落组成结构来看, 大镜山水库为富营养化水体. 然 
而, 作为寡营养水体指示种的卵形无柄轮虫在大镜山水库某些月份中也成为优势种. 因此, 在判定水体 营养水平时, 不能仅简单地根据个别轮虫指示种类, 而应从整个群落结构特征考虑.

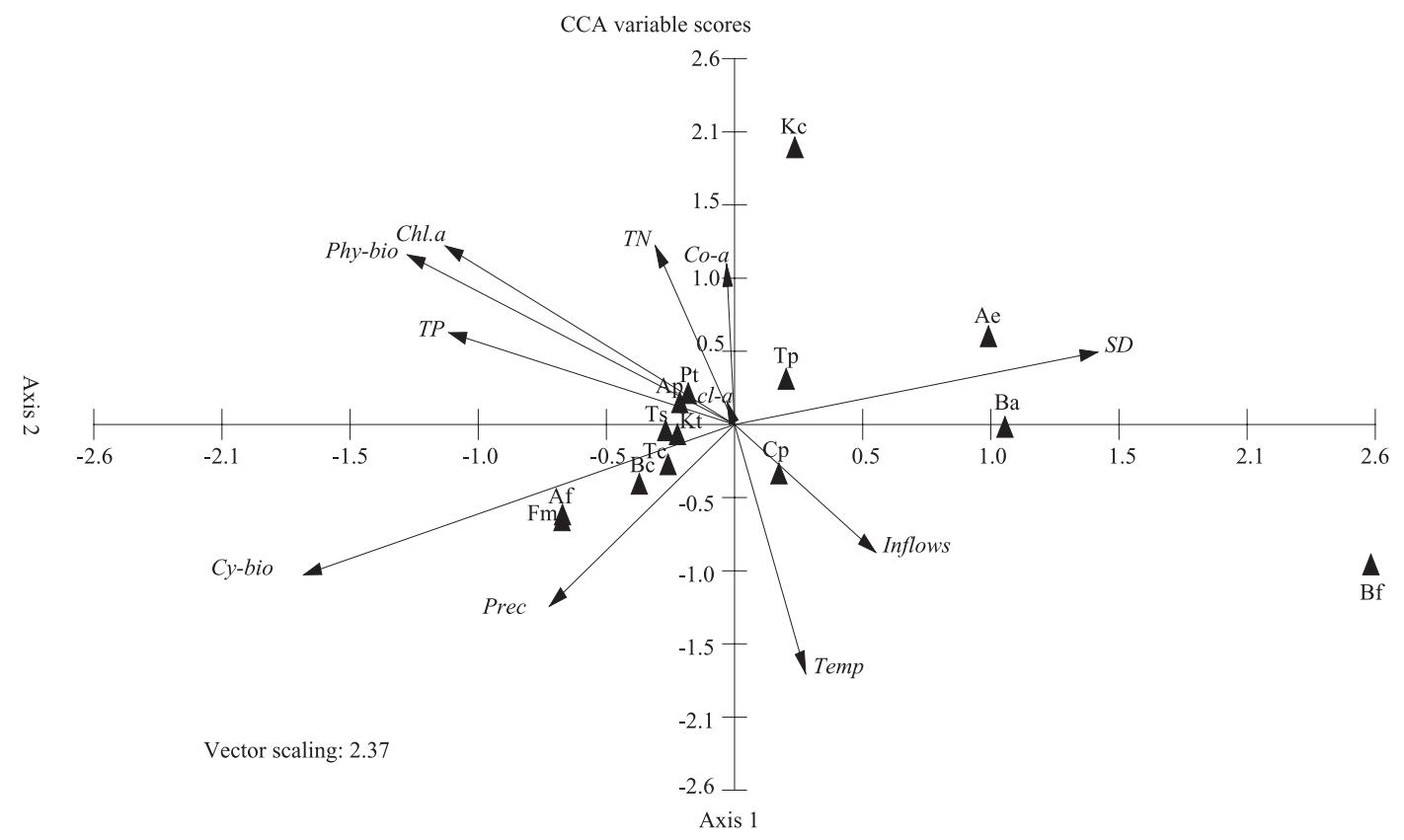

图 6 大镜山水库轮虫种类与环境变量之间的双轴等级排列

Fig.6 Ordination biplots of species and environmental variables in Dajingshan Reservoir

The code: $\mathrm{Kt}=K$. tropica, $\mathrm{Fm}=F$. maior, $\mathrm{Bf}=B$. forficula, $\mathrm{Ao}=$ A.ovalis, $\mathrm{Af}=A$. fissa, $\mathrm{Tc}=T$. capucina,

$\mathrm{Ts}=$ T.stylata, $\mathrm{Ba}=B$. angularis, $\mathrm{Cp}=C$. pelagica, $\mathrm{Kc}=K$. cochlearis, $\mathrm{Fv}=F$. Novaezealandiae, $\mathrm{Pt}=P$. trigla, $\mathrm{Ab}=A$. brightwelli, $\mathrm{Bc}=B$. Calyciflorus

水体的营养状态，在一定程度上可以影响轮虫的群落结构和动态 ${ }^{[24-25]}$. 在湖泊中, 随着营养水平的上 升, 轮虫的丰度有逐渐增加的趋势 ${ }^{[26]}$. 大镜山水库属于富营养水体, 轮虫年平均丰度为 $206.43 \mathrm{ind} . / \mathrm{L}$, 与同 地区的其它水库相比 ${ }^{[10-11]}$, 轮虫的丰度较高. 但由于水库的滞留时间比湖泊短, 水位波动大, 轮虫丰度较湖 泊低. 与同为富营养化水平的东湖 ${ }^{[27]}$ 以及广东省星湖 ${ }^{[12]}$ 相比, 大镜山水库的轮虫丰度相对较低.

一般认为, 轮虫多样性随水体营养水平的上升而下降 ${ }^{[28-29]}$. 大镜山水库营养程度较高, 轮虫种类数 及多样性指数也较低. 与湖泊相比, 水库水位变动大, 缺少水生高等植物, 轮虫的生境相对单一, 鱼类捕 食压力大. 因此与东湖以及星湖 ${ }^{[12]}$ 相比, 大镜山水库中轮虫的多样性要低, 轮虫种类数要少. 另外, 大镜 山水库中, 轮虫以硬体种类为主, 且小型个体的种类在数量上占优势, 这可能是对捕食压力的一种适应. 大镜山水库是一个富营养化水体, 有机物浓度高, 浮游生物的死亡产生大量有机碎屑, 也为小型轮虫提 供了丰富的食物.

\section{3 影响轮虫群落结构的其它环境因子}

水库作为一个受人工调节程度很高的水体, 其动物群落的动态在很大程度上与水动力学有关, 但水 库类型不同, 其影响因子可能存在差别 ${ }^{[30-32]}$. 食物和水温是影响轮虫种群密度和季节演替最重要的生态

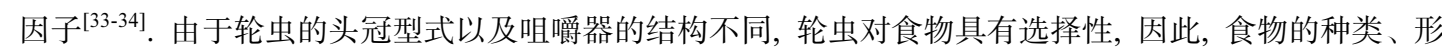
状、个体大小以及营养成分等均会影响轮虫的生长和发育, 进而影响到其群落结构 ${ }^{[33]}$. 大镜山水库中的 轮虫以滤食性种类为主, 如角突臂尾轮虫、螺形龟甲轮虫等, 它们以水体中的藻类、碎屑和细菌作为主 要食物, 而该水库富营养化状态下, 它们赖以生存的食物十分丰富. 因此, 大镜山水库中的轮虫种间竞 争不明显. 在 CCA 分析中, 蓝藻生物量、浮游植物生物量和透明度都是影响轮虫数量与组成的重要因子, 
这些因子体现了水体中食物的数量与质量. 温度一直被认为是影响轮虫发生并且引起轮虫种类季节演替 的关键因子 ${ }^{[2,35]}$. 不同种类的轮虫具有不同的温度适应性，当水温达到某种轮虫的最适温度时，其种群 增长率也最大, 水温的变化导致不同属轮虫甚至同属不同种轮虫发生季节演替 ${ }^{[36]}$. 对东湖的研究表明, 在 $20^{\circ} \mathrm{C}$ 以上的水体中, 随着水温的上升, 轮虫卵发育时间缩短, 在丰富的食物供给条件下, 使种群密度 迅速增加, 从而形成轮虫总数的高峰 ${ }^{[15]}$. 在 CCA 分析中, 水温也是影响大镜山水库轮虫数量与组成的一 个重要因子. 早春 (2 月)水温上升期, 轮虫数量出现了一个第一高峰. 这一时期内, 水库浮游植物中硅藻 的生物量约占 $20 \%-40 \%$ 左右, 食物质量相对于其它时期(蓝藻占绝对优势)较高, 食物和水温为轮虫的生 长提供了有利条件. 但随着雨季 (4 月)的到来, 轮虫数量下降, 在 5 月份有一数量峰值, 这是由降水强度 减弱所决定的. 在 CCA 分析中, 氮、磷成为影响轮虫群落数量组成的次要因子. 大镜山水库是一座富营 养化的抽水型水库, 水动力变化大, 全年的营养状态也有一定的差别. 在丰水期, 人库主要由降水组成, 导致水库的营养盐浓度低、叶绿素 a 浓度也相对较低, 这时水体交换快, 食物数量下降和水流输出量大, 均不利于轮虫数量的增殖. 在大镜山水库中, 尽管丰水期水体中的氮、磷相对低, 但浮游植物仍维持较高 的生物量, 说明氮、磷影响轮虫数量的可能性不大. 丰水期的集中降水稀释(对食物和轮虫本身的数量的 稀释)和高输出水流可能是导致水体中轮虫数量下降的直接原因. 另外, CCA 分析表明叶绿素 a 浓度、降 雨量、调水量、桡足类和枝角类的贡献相对较小, 位于次要因子. 这说明叶绿素 a 浓度、降雨量、调水量 的影响不是直接的，而是通过食物的变化来实现的; 桡足类和枝角类是水体轮虫食物的主要竞争者，但 大镜山水库富营养化程度高, 食物充足, 又缺少大型的滤食性的桡足类或枝角类, 它们对轮虫的影响也 较低, 这也是热带水体不同于温带水体一个重要方面.

\section{4 参考文献}

[1] Sladeck V. Rotifers indicators of water quality. Hydrobiologia, 1983, 100: 169-201.

[2] 黄祥飞, 胡春英, 伍焯田. 武汉东湖的轮虫. 水生生物学报, 1985, 9(2): 129-142.

[3] Snell TW, Janssen CR. Rotifers in ecotoxicology: a review. Hydrobiologia, 1995, 313/314: 231-247.

[4] Sarma SSS, Nandini S, Araiza MAF. Effect of methyl parathion-treated prey(Brachionus calyciflorus) on the population growth of the predator Asplanchna sieboldi (Rotifera). Bull Environ Contam Toxicol, 1998, 61: 135-142.

[5] Sarma SSS, Nandini S. Flores JLG. Effect of methyl parathion on the population of the rotifer Brachionus patulus (O. F. MÜller) under different algal food (Chlorella vulgaris) densities. Ecotoxicol Environ Saf, 2001, 48: 190-195.

[6] 刘建康. 东湖生态学研究(二). 北京: 科学出版社, 1995.

[7] 陈为民, 秦伯强. 太湖梅梁湾冬末春初浮游动物时空变化及其环境意义. 湖泊科学, 1998, 10(4): 10-16.

[8] 魏崇德, 俞大维. 杭州西湖浮游动物的研究. 杭州大学学报(自然科学版), 1983, 10(增刊): 1-16.

[9] 李共国, 吴芝瑛, 虞左明. 引水和疏浚工程支配下杭州西湖浮游动物的群落变化. 生态学报, 2006, 26(10): 3508-3515.

[10] 林秋奇, 赵帅营, 韩博平. 广东省水库轮虫分布特征. 生态学报, 2005, (5): 1123-1131.

[11] 林秋奇, 赵帅营, 韩博平. 新建水库轮虫和甲壳类浮游动物动态特征. 生态学杂志, 2006, 25(3): 270-276.

[12] 赵帅营, 林秋奇, 刘正文等. 南亚热带湖泊一一星湖后生浮游动物群落特征研究. 水生生物学报, 2007, 31(3): 405-413.

[13] 林少君, 贺立静, 黄沛生等. 浮游植物中叶绿素 a 提取方法的比较与分析. 生态科学, 2005, 24: 9-11.

[14] 李秋华, 韩博平. 基于 CCA 的典型调水水库浮游植物群落动态特征分析. 生态学报, 2007, 27(6): 2355-2364.

[15] 章宗涉, 黄祥飞主编. 淡水浮游生物研究. 北京: 科学出版社, 1991.

[16] Fernando CH. The freshwater zooplankton of Sri Lanka,with a discussion of tropical freshwater zooplankton composition. Int Revue Hydrobiol, 1980, 65(1): 85-125.

[17] Fernando CH, Zankai NP. The rotifera of Malaysia and Singapore with remarks on some species. Hydrobiologia, 1981, 78: 205-219.

[18] Segers H, Meester LD. Rotifera of Papua New Guinea, with the descriptions of a new Scardium Ehrenber, 1830. Arch Hydrobiol, 1994, 131: 111-125.

[19] Segers H, Dumont HJ. 102+rotifer species(Rotifera:Monogononta)in Broa reservoir(S P Brazil)on 26 August 1994 with the 
description of three new species. Hydrobiologia, 1995, 316: 183-197.

[20] Segers H. Zoogeography of the Southeast Asian Rotifera. Hydrobiologia, 2001, 446/447: 233-246.

[21] Green J. The temperate-tropical gradient of planktonic Protozoa and Rotifera. Hydrobiologia, 1994, 272: 13 -26.

[22] Stenson JAE. Fish impact on rotifer community structure. Hydrobiologia, 1982, 87: 57-64.

[23] Maemets A. Rotifers as indicators of lake types in Estonia. Hydrobiologia, 1983, 104: 357-361.

[24] Bérzińš B, Pejler B. Rotifer occurrence in relation to temperature. Hydrobiologia, 1989, 175: 223-231.

[25] Bérzińš B, Pejler B. Rotifer occurrence in relation to trophic degree. Hydrobiologia, 1989, 182: 171-180.

[26] Nilssen JP. Tropical lakes- functional ecology and future development: The need for a process-orientated approach Hydrobiologia, 1984, 113: 231-242.

[27] 诸葛燕, 黄祥飞. 武汉东胡浮游轮虫的种类演替和数量动态. 见: 刘建康主编. 东湖生态学研究(二). 北京: 科学出版社, 1995.

[28] 谢 平, 诸葛燕, 戴 䒭等. 水体富营养化对浮游生物群落多样性的影响. 水生生物学报, 1996, 20(增刊): 30-37.

[29] Shao ZJ, Xie P, Zhuge Y. Long-term changes of planktonic rotifers in a subtropical Chinese lake dominated by filter-feeding fishes. Freshwater Biology, 2001, 46: 973-986.

[30] George DG, Reynolds CS. Zooplankton-phytoplankton interactions: the case for refining methods, measurements and models. Aquatic Ecology, 1997, 31: 59-71.

[31] Devetter M. Influence of environmental factors on the rotifer assemblage in an artificial lake. Hydrobiologia, 1988, 387/388 171-178.

[32] González EJ. Nutrient enrichment and zooplankton effects on the phytoplankton community in microcosms from EI Andino reservoir(Venezuela). Hydrobiologia, 2000, 434: 81-96

[33] Dumont HJ. Biogeography of Rotifers. Hydrobiologia, 1977, 104: 19-30.

[34] Gulati RD. Zooplankton structure in the Loosdrecht lakes in relation to trophic status and recent restoration measures. Hydrobiologia, 1990, 191: 173-188

[35] Hessen DO, Faafeng BA, Andersen T. Replacement of herbivore zooplankton species along gradients of ecosystem productivity and fish predation pressure. Can J Fish aquqt Sci, 1995, 52: 733-742.

[36] Herzig A. The analysis of planktonic rotifer populations: A plea for long-term investigations. Hydrobiologia, 1987, 147: $163-180$. 